\title{
Polypharmacy and Nutraceuticals in Veterans: Pros and Cons
}

\author{
Tommaso Sciarra ${ }^{1 \star}$, Mario Ciccotti ${ }^{1,2}$, Paola Aiello ${ }^{2,3}$, Paola Minosi ${ }^{2,4}$, Diego Munzi ${ }^{1}$, \\ Cosimo Buccolieri ${ }^{1}$, Ilaria Peluso ${ }^{3}$, Maura Palmery ${ }^{2}$ and Florigio Lista ${ }^{5}$ \\ ${ }^{1}$ Joint Veteran Center, Scientific Department, Army Medical Center, Rome, Italy, ${ }^{2}$ Department of Physiology and \\ Pharmacology "V. Erspamer," La Sapienza University of Rome, Rome, Italy, ${ }^{3}$ Research Centre for Food and Nutrition, Council \\ for Agricultural Research and Economics (CREA-AN), Rome, Italy, ${ }^{4}$ National Center for Drug Research and Evaluation, \\ Istituto Superiore di Sanità, Rome, Italy, ${ }^{5}$ Scientific Department, Army Medical Center, Rome, Italy
}

Keywords: veterans, polypharmacy, nutraceuticals, food-drug interactions, interprofessional interventions

\section{OPEN ACCESS}

Edited by:

Pietro Minuz, University of Verona

Italy

Reviewed by:

Maciej Banach,

Medical University of Lodz,

Poland

*Correspondence:

Tommaso Sciarra

sciarratommaso@hotmail.com

Specialty section:

This article was submitted to Inflammation Pharmacology,

a section of the journal

Frontiers in Pharmacology

Received: 25 January 2019

Accepted: 06 August 2019

Published: 10 September 2019

Citation:

Sciarra T, Ciccotti M, Aiello P, Minosi $P$, Munzi D, Buccolieri $C$, Peluso I, Palmery M and Lista F (2019) Polypharmacy and

Nutraceuticals in Veterans:

Pros and Cons.

Front. Pharmacol. 10:994.

doi: 10.3389/fphar.2019.00994
The presence of multiple chronic conditions (multi-morbidity) is common in veterans, in particular among the elderly (Golchin et al., 2015). Many of veterans' injuries have been described as a polytrauma clinical triad, which refers to the co-occurrence (Figure 1) of post-traumatic stress disorder (PTSD), chronic pain, and traumatic brain injury (TBI). While the concomitant injuries (Figure 1) accompanying TBI may be manifold, including fractures, amputations, burns, spinal cord injury, eye injury, and auditory trauma, the two most prevalent and functionally disabling conditions may be PTSD and chronic pain (Lew et al., 2009). Although it has been recently suggested that treatment with opioids is not superior to treatment with nonopioid medications, including acetaminophen, for improving pain-related function in patients with chronic pain (Krebs et al., 2018), paracetamol pharmacokinetic is affected by nutraceuticals and some plant foods (Figure 1) (Abdel-daim et al., 2018).

Moreover, chronic pain symptoms are often comorbid with psychiatric conditions, such as depression (Runnals et al., 2013), substance use disorders (Figure 1) (Caldeiro et al., 2008), functional disability, and growing epidemic of prescription opioid abuse (Wilder et al., 2016). PTSD has been associated not only with cardiovascular diseases, such as hypertension (Abouzeid et al., 2012), but also with cancer (Boscarino, 2008), type 2 diabetes (Boyko et al., 2010), and poor health, including obesity (Figure 1) (Smith et al., 2015).

As a consequence, the use of five or more medications (polypharmacy) (Figure 1) to control symptoms, in order to prevent both disease complications and the development of new medical conditions, is very common in veterans, so the accumulation of multiple medications represents a critical patient safety issue. In fact, the greater the number of total prescribed medications, the greater the likelihood of prescribing a potentially harmful drug. A suitable polypharmacy can extend life expectancy and maintain quality of life when medicines are prescribed according to the best evidence and their usage is optimized. However, it has been documented that too often polypharmacy can be a detriment in case of inappropriate prescriptions (Soerensen et al., 2016) and potential prescription omissions (Rongen et al., 2016). One possible solution is deprescribing, namely, the intentional, proactive, rational discontinuation of a medication that is no longer indicated or for which the potential risk outweighs the potential benefits. The issue becomes more complicated when certain medical guidelines [e.g., those for chronic heart failure (Yancy et al., 2017)] require treatment with multiple medications to achieve the optimal clinical effect.

Furthermore, polypharmacy is sometimes associated with poor clinical outcomes, especially in older adults, including falls, frailty (Figure 1), impaired cognition, increased hospital admissions, and adverse drug reactions (Gnjidic et al., 2012). The most worrisome consequence of polypharmacy is the occurrence of therapeutic failures, adverse drug withdrawal events, and drug-drug interactions 


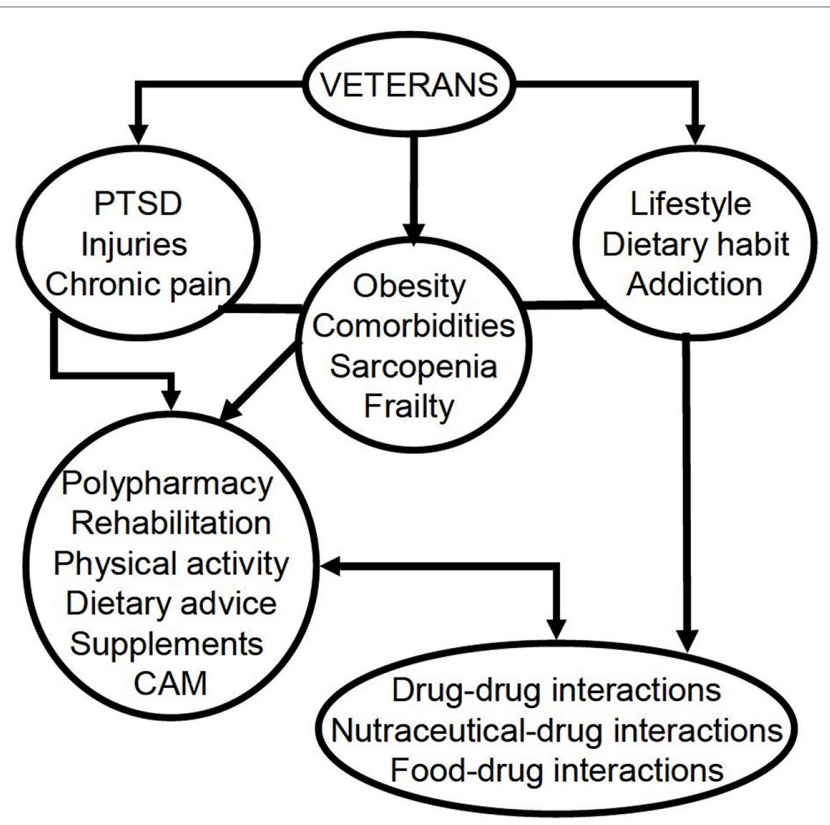

FIGURE 1 | Factors that account for the need of interprofessional approaches (including physical medicine and rehabilitation clinicians, pharmacologists, and nutritionists). PTSD, post-traumatic stress disorder; CAM, complementary and alternative medicine.

leading to hospitalization. All of these events are associated with similarly negative economic outcomes, such as increased drug cost and costs associated with more frequent usage of health services (Fried et al., 2014). On the other hand, the impact of some drugs on dietary habit and nutritional status is well documented (Lappin et al., 2018; Little, 2018). It is well known that polypharmacy, malnutrition, and sarcopenia are major causes of frailty (Figure 1) and that rehabilitation, nutrition, and interventions with mixed outcomes are important to improve disability (Singh et al., 2012; Little, 2018; Roberts et al., 2018; Wakabayashi, 2018). Despite nutritional supplements being taken into consideration in malnourishment in polypharmacy (Gaddey and Holder, 2014), another phenomenon that should not be underestimated is the trend to use vitamins and nutritional supplements instead of prescription medications. It can be assumed that costs, treatment beliefs, and/or health system distrust are the leading factors which have been influencing this trend. In the United States, especially among veterans, there is a penchant for the use of vitamins and supplements, which represent the most common form of complementary and alternative medicine (CAM) currently in use (Goldstein et al., 2014).

According to a report on the website (US Food and Drug Administration, 2008), many patients use them in addition to or instead of (nearly one in five Americans) their prescription medications. At the same time, the use of CAM (Figure 1), including acupuncture, deep-breathing exercises, massage therapy, meditation, naturopathy, and yoga, is growing, specifically among patients with chronic conditions and those taking prescription drugs (Gardiner et al., 2006; Nahin et al.,
2009). As regards veterans, a longing for a holistic approach to health care and the lack of trust in the health system are more common in those who use CAM (Kroesen et al., 2002). In particular, it has been shown that $75 \%$ of veterans, as well as the general population, used vitamins and supplements, whereas 18\% substituted drugs (US Food and Drug Administration, 2008). Among the latter, 25\% replaced hyperlipidemia medications, $17 \%$ the anxiolytics/antidepressants, $15 \%$ those for both arthritis/back pain and hot flashes, $10 \%$ the antidiabetic drugs, and 8\% those for hypertension (Goldstein et al., 2014). Patti et al. (2017) suggested that the use of nutraceuticals containing omega-3, polyphenols, vitamins, and trace elements could be useful in contrasting metabolic syndromes. In addition to this, a recent meta-analysis has pointed out the improvement of moderate hypercholesterolemia determined by supplementation with red yeast rice (Fogacci et al., 2019). It has been reported that red yeast rice supplementation is safe and not associated with increased incidence of muscular adverse effects (Fogacci et al., 2019). Furthermore, bergamot, red yeast rice, soluble fiber, berberine, artichokes, plant sterols, and stanols have been suggested as an alternative or additional therapy to statins, alone or in combination with each other (e.g., with drugs, such as ezetimibe), in statin-intolerant patients (Cicero et al., 2017; Banach et al., 2018). On the contrary, Ward et al. (2018) reported that in their clinical practice experience, $1 / 18$ patients with statin-associated muscle symptoms (SAMS) (5.5\%) had side effects after nutraceutical treatment (muscle ache/stiffness and intolerance).

On the other hand, the risk of statin-induced serious muscle injury, including rhabdomyolysis, is $<0.1 \%$, and the risk of serious hepatotoxicity is $\approx 0.001 \%$ (Newman et al., 2019), and in a metaanalysis, statins did not seem to modify rhabdomyolysis, myalgia, or rise in creatine kinase (Tramacere et al., 2019). It must be borne in mind that fermented red rice contains monacolin $\mathrm{K}$, having the same formula of lovastatin (US National Library of Medicine ${ }^{1}$ ). In 2014, Italy was ranked first in Europe for consumption of nutraceuticals, and the presence of some problems related to their use has been reported by the Società Italiana per lo Studio dell'Aterosclerosi (SISA) (Averna and Pirro, 2017). The improper vigilance and the strong belief in the safety of natural products are cultural limits to be demolished through scientific information (Averna and Pirro, 2017). A significant percentage of people who consume nutraceuticals declared to have not purchased them as a result of medical advice (Averna and Pirro, 2017). In spite of the uncertainties about the efficacy of herbal preparations and dietary supplements, users who want to check their health personally often believe that herbal preparations and dietary supplements are natural and have fewer side effects (Wu et al., 2014). Actually, recent US data indicated that the use of a combination of dietary supplement products is most commonly associated with side effects (Austin et al., 2016; Knapik et al., 2016); furthermore, potential interactions can also occur between drugs and herbal/ nutritional supplements (Figure 1) (Loya et al., 2009) with significant consequences, such as an increased risk of adverse

${ }^{1}$ US National Library of Medicine. Available online at https://pubchem.ncbi.nlm. nih.gov/\#query=Monacolin $\% 20 \mathrm{~K}$ 
drug reactions probably due to the induction or inhibition of cytochrome P450 isoenzymes (Henderson et al., 2002); for example, Hypericum perforatum, known for the antidepressant and sedative activity of its phytocomplex, has the ability to accelerate cytochrome P450, giving multiple interactions with different classes of drugs such as selective serotonin reuptake and monoamine oxidase inhibitor (Lantz et al., 1999), warfarin (Jiang et al., 2004), digoxin (Muller et al., 2004), statins (Sugimoto et al., 2001), and all cytochrome P450 metabolized agents (Markowitz et al., 2003). Moreover, coadministration of ephedra (Ephedra sinica), which can increase blood pressure and decrease platelet aggregation, and nonsteroidal anti-inflammatory drugs may potentiate the risk of cerebral hemorrhage and gastrointestinal ulcer bleeding (Meng and Liu, 2014). Possible interactions with drugs have also been suggested for mineral-fortified foods and fruit juices, which are able to influence the bioequivalence of levofloxacin and ciprofloxacin (Neuhofel et al., 2002; Amsden et al., 2003; Wallace et al., 2003). Accordingly, the Department of Veterans Affairs has dedicated a special section on its website to all the possible interactions between food and drugs, also indicating nutraceuticals (Figure 1) to be taken carefully if you are undergoing a polypharmacy (US Department of Veterans Affairs $^{2}$ ). On one hand, drug-drug interactions are included in most pharmacovigilance systems owing to their widely recognized clinical relevance; on the other hand, nutrient-drug interactions are still underexplored, and their appraisal is not part of the clinical routine, despite being supported by a lot of data (Péter et al., 2017). Therefore, it would seem necessary to proceed with a systematic evaluation of such interactions by means of an appropriate analysis both of a possible influence of the nutritional status in the drug action and of the effect of adverse drug reactions on the nutritional status (Péter et al., 2017). This systematic analysis obviously has to provide for a nutritional appraisal throughout the phases of drug development and post-marketing surveillance. Adverse drug effects in clinical practice, in particular those related to nutrition, should be reported spontaneously, and a special attention should be paid to taking into account malnutrition, the global nutritional status, and the dietary supplements used (Péter et al., 2017). Particularly, regarding nutritional status, Becerra et al. (2016) have pointed out the extreme necessity to carry out health promotion measures among veterans in order to encourage a healthy diet in this population, especially those with limited access to healthy food options. In fact, negative dietary practices have come to light among veterans, which are associated with food insecurity. In this regard, the Department of Veteran Affairs provides guidance to veterans about how a healthy diet, rich in fruits and vegetables, accompanied by movement, can be useful in combating overweight and related diseases (Rutledge et al., 2017). Facilitating healthy diets, physical activity, and weight management in the veteran population is an important public health challenge (Figure 1). In fact, a cross-sectional analysis reported that approximately $37 \%$ and $33 \%$ of women and men

${ }^{2}$ US Department of Veterans Affairs. Available online at https://www.nutrition. va.gov/Food_Drug_Interactions.asp (last access 06-11-2018). veterans are obese, respectively (Das et al., 2005), while others demonstrated higher prevalence of overweight status (Koepsell et al., 2009) and greater waist circumference among veterans (Koepsell et al., 2012) as compared with the civilian population. Such a prevalence of overweight and obesity among veterans may be due to their dietary practices. In fact, recent studies have found that military service impacts soldiers' food environment and food security, which then influences eating behavior and food choices both during military service and following discharge (Smith et al., 2009; Wang et al., 2015; Widome et al., 2015). During this time frame, veterans consume high-fat and high-carbohydrate foodstuffs, with a preference for specific food items (burgers and fries) (Smith et al., 2009), which is influenced by their low cost, an important aspect that could further be driving vulnerable populations away from healthier items, which usually are more expensive (Drewnowski and Darmon, 2005a; Drewnowski and Darmon, 2005b; Jetter and Cassady, 2006).

A diet high in fruits and vegetables is associated with decreased risk for chronic diseases such as cardiovascular disease, hypertension, diabetes, and cancer (Adams and Standridge, 2006); therefore, it may play an important role in reducing veterans' health risks.

In our opinion, the Mediterranean Diet Pyramid could be the basis for integrative medicine for veterans with disabilities, but patient-centered and interprofessional approaches represent the real added value for the best health care management. A comprehensive approach should also include physical medicine and rehabilitation clinicians, pharmacists, and nutritionist in order to prevent malnutrition, selfprescription of CAM, and food-drug and/or nutraceuticaldrug interactions according to a biopsychosocial model (Figure 1) (Ciccotti et al., 2018). Personalized health care for chronic noncommunicable diseases that impact quality of life should consider gut microbiota, genetic and epigenetic factors (Peluso et al., 2018a), and moods and hormones involved in stress response (Peluso et al., 2018b) rather than functional status. In particular, as previously suggested, in order to avoid potential food-drug interactions, plant foods should be chosen within those containing low phytochemicals and high micronutrients. If this aim is difficult to reach, vitamin and/ or mineral supplementation can be recommended (top of the pyramid for veterans, Ciccotti et al., 2018).

\section{AUTHOR CONTRIBUTIONS}

MC, PA, and PM developed the concept and wrote the paper. $\mathrm{DM}$ contributed to the bibliographic research. TS coordinated the research and conception work. MP, FL, CB, and IP drafted the work and revised it for important intellectual content.

\section{FUNDING}

This work is an activity of the project AMAMP (2019-2021), funded by Ministero della Difesa, Italy. 


\section{REFERENCES}

Abdel-daim, M., Abushouk, A. I., Reggi, R., Yarla, N. S., Palmery, M., and Peluso, I. (2018). Association of antioxidant nutraceuticals and acetaminophen (paracetamol): friend or foe? J. Food Drug Anal. 26 (2S), S78-S87. doi: 10.1016/j. jfda.2017.11.004

Abouzeid, M., Kelsall, H. L., Forbes, A. B., Sim, M. R., and Creamer, M. C. (2012). Posttraumatic stress disorder and hypertension in Australian veterans of the 1991 Gulf War. J. Psychosom. Res. 72, 33-38. doi: 10.1016/j. jpsychores.2011.08.002

Adams, S. M., and Standridge, J. B. (2006). What should we eat? Evidence from observational studies. South Med. J. 99 (7), 744-748. doi: 10.1097/01. smj.0000220887.52952.f0

Amsden, G. W., Whitaker, A. M., and Johnson, P. W. (2003). Lack of bioequivalence of levofloxacin when coadministered with a mineralfortified breakfast of juice and cereal. J. Clin. Pharmacol. 43, 990-995. doi: 10.1177/0095399703257218

Austin, K. G., Farina, K., and Lieberman, H. R. (2016). Self-reported side-effects associated with use of dietary supplements in an armed forces population. Drug Test Anal. 8, 287-295. doi: 10.1002/dta.1905

Averna, M., and Pirro, M. (2017). Nutraceutica: IL punto di vista delle società scientifiche nutraceutica: il punto di vista della sisa (Società Italiana per lo Studio dell' Aterosclerosi). Giornale Italiano di Farmacoeconomia $e$ Farmacoutilizzazione 9, 159-161.

Becerra, M. B., Hassija, C. M., and Becerra, B. J. (2016). Food insecurity is associated with unhealthy dietary practices among US veterans in California. Public Health Nutr. 20, 2569-2576. doi: 10.1017/S1368980016002147

Banach, M., Patti, A. M., Giglio, R. V., Cicero, A. F. G., Atanasov, A. G., Bajraktari, G., et al. (2018). International Lipid Expert Panel (ILEP). The role of nutraceuticals in statin intolerant patients. J. Am. Coll. Cardiol. 72 (1), 96-118. doi: 10.1016/j.jacc.2018.04.040

Boscarino, J. A. (2008). A prospective study of PTSD and early-age heart disease mortality among Vietnam veterans: implications for surveillance and prevention. Psychosom. Med. 70, 668-676. doi: 10.1097/PSY.0b013e31817bccaf

Boyko, E. J., Jacobson, I. G., Smith, B., Ryan, M. A. K., Hooper, T. I., Amoroso, P. J., et al. (2010). Risk of diabetes in US military service members in relation to combat deployment and mental health. Diabetes Care 33 (8), 1771-1777. doi: $10.2337 / \mathrm{dc10}-0296$

Caldeiro, R. M., Malte, C. A., Calsyn, D. A., Baer, J. S., Nichol, P., Kivlahan, D. R., et al. (2008). The association of persistent pain with out-patient addiction treatment outcomes and service utilization. Addiction 103 (12), 1996-2005. doi: 10.1111/j.1360-0443.2008.02358.x

Cicero, A. F. G., Colletti, A., Bajraktari, G., Descamps, O., Djuric, D. M., Ezhov, M., et al. (2017). Lipid-lowering nutraceuticals in clinical practice: position paper from an International Lipid Expert Panel. Nutr. Rev. 75, 731-767. doi: 10.1093/ nutrit/nux047

Ciccotti, M., Raguzzini, A., Sciarra, T., Catasta, G., Aiello, P., and Buccolieri, C. (2018). Nutraceutical-based integrative medicine: adopting a Mediterranean diet pyramid for attaining healthy ageing in veterans with disabilities. Curr. Pharm. Des. 24, 4186-4196. doi: 10.2174/1381612824666181003113444

Das, S. R., Kinsinger, L. S., Yancy, W. S., Wang, A., Ciesco, E., Burdick, M., et al. (2005). Obesity prevalence among veterans at Veterans Affairs medical facilities. Am. J. Prev. Med. 28, 291-294. doi: 10.1016/j.amepre.2004.12.007

Drewnowski, A., and Darmon, N. (2005a). Food choices and diet costs: an economic analysis. Am. Soc. Nutr. Sci. 135, 900-904. doi: 10.1093/jn/135.4.900

Drewnowski, A., and Darmon, N. (2005b). The economics of obesity: dietary energy density and energy cost. Am. J. Clin. Nutr. 82, 265-273. doi: 10.1093/ ajcn/82.1.265S

Fogacci, A. F., Banach, M., Dimitri, P., Bruckert, E., Toth, P. P., and Watts, G. F. (2019). Graphical abstract SC. Pharmacol. Res. 143, 1-16. doi: 10.1016/j.phrs.2019.02.028

Fried, T. R., O'Leary, J., Towle, V., Goldstein, M. K., Trentalange, M., and Martin, D. K. (2014). Health outcomes associated with polypharmacy in communitydwelling older adults: a systematic review. J. Am. Geriatr. Soc. 62 (12), 2261-2272. doi: 10.1111 /jgs. 13153

Gaddey, H. L., and Holder, K. (2014). Unintentional weight loss in older adults. Am. Fam. Physician. 89, 718-722. doi: 10.1503/cmaj.lll-2042

Gardiner, P., Graham, R. E., Legedza, A. T. R., Eisenberg, D. M., and Phillips, R. S. (2006). Factors associated with dietary supplement use among prescription medication users. Arch. Intern. Med. 166, 1968-1974. doi: 10.1001/ archinte.166.18.1968

Gnjidic, D., Hilmer, S. N., Blyth, F. M., Naganathan, V., Waite, L., Seibel, M. J., et al. (2012). Polypharmacy cutoff and outcomes: five or more medicines were used to identify community-dwelling older men at risk of different adverse outcomes. J. Clin. Epidemiol. 65 (9), 989-995. doi: 10.1016/j.jclinepi.2012.02.018

Golchin, N., Frank, S. H., Vince, A., Isham, L., and Meropol, S. B. (2015). Polypharmacy in the elderly. J. Res. Pharm. Pract. 4 (2), 85-88. doi: 10.4103/2279-042X.155755

Goldstein, J. N., Long, J. A., Arevalo, D., Ibrahim, S. A., and Mao, J. J. (2014). US veterans use vitamins and supplements as substitutes for prescription medication. Med. Care 52, S65-S69. doi: 10.1097/MLR.0000000000000199

Henderson, L., Yue, Q. T., Bergquist, C., Gerden, B., and Arlett, P. (2002). St John's wort (Hypericum perforatum): drug interactions and clinical outcomes. Clin. Pharmacol. 54, 349-356. doi: 10.1046/j.1365-2125.2002.01683.x

Jetter, K. M., and Cassady, D. L. (2006). The availability and cost of healthier food alternatives. Am. J. Prev. Med. 30, 38-44. doi: 10.1016/j.amepre.2005.08.039

Jiang, X., Williams, K. M., Liauw, W. S., Ammit, A. J., Roufogalis, B. D., Duke, C. C., et al. (2004). Effect of St John's wort and ginseng on the pharmacokinetics and pharmacodynamics of warfarin in healthy subjects. Br. J. Clin. Pharmacol. 57, 592-599. doi: 10.1111/j.1365-2125.2003.02051.x

Knapik, J. J., Trone, D. W., Austin, K. G., Steelman, R. A., Farina, E. K., and Lieberman, H. R. (2016). Prevalence, adverse events, and factors associated with dietary supplement and nutritional supplement use by US Navy and Marine Corps personnel. J. Acad. Nutr. Diet. 116 (9), 1423-1442 doi: 10.1016/j. jand.2016.02.015

Koepsell, T. D., Forsberg, C. W., and Littman, A. J. (2009). Obesity, overweight, and weight control practices in U.S. veterans. Prev. Med. (Baltim) 48, 267-271. doi: 10.1016/j.ypmed.2009.01.008

Koepsell, T. D., Littman, A. J., and Forsberg, C. W. (2012). Obesity, overweight, and their life course trajectories in veterans and non-veterans. Obesity 20, 434-439. doi: 10.1038/oby.2011.2

Krebs, E. E., Gravely, A., Nugent, S., Jensen, A. C., Deronne, B., Goldsmith, E. S., et al. (2018). Effect of opioid vs nonopioid medications on pain-related function in patients with chronic back pain or hip or knee osteoarthritis pain the SPACE randomized clinical trial. JAMA 6 (319), 872-882. doi: 10.1001/jama.2018.0899

Kroesen, K., Baldwin, C. M., Brooks, A. J., and Bell, I. R. (2002). US military veterans' perceptions of the conventional medical care system and their use of complementary and alternative medicine. Fam. Pract. 19, 57-64. doi: 10.1093/ fampra/19.1.57

Lantz, M. S., Buchalter, E., and Giambanco, V. J. (1999). St. John's wort and antidepressant drug interactions in the elderly. Geriatr. Psychiatry Neurol. 12, 7-10. doi: 10.1177/089198879901200103

Lappin, J. M., Wijaya, M., Watkins, A., Morell, R., Teasdale, S., Lederman, O., et al. (2018). Cardio-metabolic risk and its management in a cohort of clozapine-treated outpatients. Schizophr. Res. 199, 367-373. doi: 10.1016/j. schres.2018.02.035

Lew, H. L., Otis, J. D., Tun, C., Kerns, R. D., Clark, M. E., and Cifu, D. X. (2009). Prevalence of chronic pain, posttraumatic stress disorder, and persistent postconcussive symptoms in OIF/OEF veterans: polytrauma clinical triad. J. Rehabil. Res. Dev. 46 (6), 697-702. doi: 10.1682/JRRD.2009.01.0006

Little, M. O. (2018). Updates in nutrition and polypharmacy. Curr. Opin. Clin. Nutr. Metab. Care. 21, 4-9. doi: 10.1097/MCO.0000000000000425

Loya, M. A., González-Stuart, A., and Rivera, O. J. (2009). Prevalence of polypharmacy, polyherbacy, nutritional supplement use and potential product interactions among older adults living on the United States-Mexico border. Drugs Aging 26, 423-436. doi: 10.2165/00002512-200926050-00006

Markowitz, J. S., Donovan, J. L., De Vane, C. L., Taylor, R. M., Ruan, Y., Wang, J. S., et al. (2003). Effect of St John's wort on drug metabolism by induction of cytochrome P450 3A4 enzyme. JAMA 290, 1500-1504. doi: 10.1001/ jama.290.11.1500

Meng, Q., and Liu, K. (2014). Pharmacokinetic interactions between herbal medicines and prescribed drugs: focus on drug metabolic enzymes and transporters. Curr. Drug Metab. 15 (8), 791-807. doi: 10.2174/138920021666 6150223152348

Muller, S. C., Uehleke, B., Woehling, H., Petzsch, M., Majcher-Peszynska, J., Hehl, E. M., et al. (2004). Effect of St John's wort dose and preparations on the pharmacokinetics of digoxin. Clin. Pharmacol. Ther. 75, 546-557. doi: 10.1016/j.clpt.2004.01.014 
Nahin, R. L., Pecha, M., Welmerink, D. B., Sink, K., Dekosky, S. T., and Fitzpatrick, A. L. (2009). Concomitant use of prescription drugs and dietary supplements in ambulatory elderly people: clinical investigations. J. Am. Geriatr. Soc. 57, 1197-1205. doi: 10.1111/j.1532-5415.2009.02329.x

Neuhofel, A. L., Wilton, J. H., Victory, J. M., Hejmanowsk, L. G., and Amsden, G. W. (2002). Lack of bioequivalence of ciprofloxacin when administered with calcium-fortified orange juice: a new twist on an old interaction. J. Clin. Pharmacol. 42, 461-466. doi: 10.1177/00912700222011391

Newman, C. B., Preiss, D., Tobert, J. A., Jacobson, T. A., Page, R. L., Goldstein, L. B., et al. (2019). Statin safety and associated adverse events: a scientific statement from the American Heart Association. Arterioscler Thromb. Vasc. Biol. 39 (2), e38-e81. doi: 10.1161/ATV.0000000000000073

Patti, A. M., Al-rasadi, K., Giglio, R. V., Nikolic, D., Mannina, C., Castellino, G., et al. (2017). State of the art paper Natural approaches in metabolic syndrome management. Arch. Med. Sci. 14 (2), 422-441. doi: 10.5114/aoms.2017.68717

Peluso, I., Abdel-Daim, M., Yarla, N. S., and Kamal, M. A. (2018a). Complementary and integrative medicine: personalized health care for cancer and chronic inflammatory diseases. Curr. Pharm. Des. 24 (35), 4091-2. doi: 10.2174/1381 61282435190117102756

Peluso, I., Palmery, M., Yarla, N. S., Perry, G., and Kamal, M. A. (2018b). From oxidative stress to ageing via lifestyle, nutraceuticals, polypharmacy, and neuropsychological factors. Oxid. Med. Cell Longev. doi: 10.1155/2018/6352689

Péter, S., Navis, G., De Borst, M. H., Von Schacky, C., Claire, A., Luiten, B. V. O., et al. (2017). Public health relevance of drug-nutrition interactions. Eur. J. Nutr. 56, 23-36. doi: 10.1007/s00394-017-1510-3

Roberts, P. S., Otr, L., Aronow, H. U., and Riggs, R. V. (2018). Frailty in a post-acute care population: a scoping review. $P M \hookleftarrow R$. 10 (11), 1211-1220. doi: 10.1016/j. pmrj.2018.03.009

Rongen, S., Kramers, C., O'Mahony, D., Feuth, T. B., Olde Rikkert, M. G., and Ahmed, A. I. (2016). Potentially inappropriate prescribing in older patients admitted to psychiatric hospital. Int. J. Geriatr. Psychiatry 31, 137-145. doi: $10.1002 /$ gps.4302

Runnals, J. J., Van Voorhees, E., Robbins, A. T., Brancu, M., Straits-Troster, K., Beckham, J. C., et al. (2013). Self-reported pain complaints among Afghanistan/ Iraq era men and women veterans with comorbid posttraumatic stress disorder and major depressive disorder. Pain Med. 14 (10), 1529-1533. doi: 10.1111/pme.12208

Rutledge, T., Skoyen, J. A., Wiese, J. A., Ober, K. M., and Woods, G. N. (2017). A comparison of MOVE! versus TeleMOVE programs for weight loss in veterans with obesity. Obes. Res. Clin. Pract. 11 (3), 344-351. doi: 10.1016/j.orcp.2016.11.005

Singh, N. A., Quine, S., Clemson, L. M., Williams, E. J., Williamson, D. A., Stavrinos, T. M., et al. (2012). Effects of high-intensity progressive resistance training and targeted multidisciplinary treatment of frailty on mortality and nursing home admissions after hip fracture: a randomized controlled trial. JMDA 13, 24-30. doi: 10.1016/j.jamda.2011.08.005

Smith, C., Klosterbuer, A., and Levine, A. S. (2009). Military experience strongly influences post-service eating behavior and BMI status in American veterans. Appetite 52, 280-289. doi: 10.1016/j.appet.2008.10.003

Smith, B. N., Tyzik, A. L., Neylan, T. C., and Cohen, B. E. (2015). PTSD and obesity in younger and older veterans: results from the mind your heart study. Psychiatry Res. 229 (3), 895-900. doi: 10.1016/j.psychres.2015.07.044

Soerensen, A. L., Nielsen, L. P., Poulsen, B. K., Lisby, M., and Mainz, J. (2016). Potentially inappropriate prescriptions in patients admitted to a psychiatric hospital. Nord. J. Psychiatry. 70 (5), 365-373. doi: 10.3109/08039488.2015.1127996
Sugimoto, K., Ohmori, M., Tsuruoka, S., Nishiki, K., Kawaguchi, A., Harada, K., et al. (2001). Different effects of St John's wort on the pharmacokinetics of simvastatin and pravastatin. Clin. Pharmacol. Ther. 70, 518-524. doi: 10.1067/mcp.2001.120025

Tramacere, I., Boncoraglio, G. B., Banzi, R., Del Giovane, C., Kwag, K. H., Squizzato, A., et al. (2019). Comparison of statins for secondary prevention in patients with ischemic stroke or transient ischemic attack: a systematic review and network meta-analysis. BMC Med. 17 (1), 67. doi: 10.1186/ s12916-019-1298-5

US Food and Drug Administration. (2008). 2008 Health and diet survey: topline frequencies (weighted). Available at: http://www.fda.gov/food/ foodscienceresearch/consumerbehaviorresearch/ucm193895.htm.

Wakabayashi, H. (2018). Rehabilitation pharmacotherapy: a combination of rehabilitation and pharmacotherapy. J. Gen. Fam. Med. 19 (2), 43-44. doi: $10.1002 /$ jgf 2.163

Wallace, A. W., Victory, J. M., and Amsden, G. W. (2003). Lack of bioequivalence when levofloxacin and calcium-fortified orange juice are coadministered to healthy volunteers. J. Clin. Pharmacol. 3, 539-544. doi: 10.1177/0091270003253399

Wang, E. A., McGinnis, K. A., Goulet, J., Bryant, K., Gibert, C., Leaf, D. A., et al. (2015). Food insecurity and health: data from the veterans aging cohort study. Public Health Rep. 130, 261-268. doi: 10.1177/003335491513000313

Ward, N. C., Pang, J., Ryan, J. D. M., and Watts, G. F. (2018). Nutraceuticals in the management of patients with statin-associated muscle symptoms, with a note on real-world experience. Clin. Cardiol. 41, 159-165. doi: 10.1002/ clc. 22862

Widome, R., Jensen, A., Bangerter, A., and Fu, S. S. (2015). Food insecurity among veterans of the US wars in Iraq and Afghanistan. Public Health Nutr. 18, 844-849. doi: 10.1017/S136898001400072X

Wilder, C. M., Miller, S. C., Tiffany, E., Winhusen, T., Winstanley, E. L., and Stein, M. D. (2016). Risk factors for opioid overdose and awareness of overdose risk among veterans prescribed chronic opioids for addiction or pain. J. Addict Dis. 35 (1), 42-51. doi: 10.1080/10550887.2016.1107264

Wu, C. H., Wang, C. C., Tsai, M. T., Huang, W. T., and Kennedy, J. (2014). Trend and pattern of herb and supplement use in the United States: results from the 2002, 2007, and 2012 national health interview surveys. Evid. Based Complement Altern. Med. 2014. doi: 10.1155/2014/872320

Yancy, C. W., Jessup, M., Bozkurt, B., Butler, J., Casey, D. E., Jr., Colvin, M. M., et al. (2017). ACC/AHA/HFSA focused update of the 2013 ACCF/AHA guideline for the management of heart failure: a report of the American College of Cardiology/American Heart Association Task Force on Clinical Practice Guidelines and the Heart Failure Society of America. J. Card. Fail. 23 (8), 628-651. doi: 10.1016/j.cardfail.2017.04.014

Conflict of Interest Statement: The authors declare that the research was conducted in the absence of any commercial or financial relationships that could be construed as a potential conflict of interest.

Copyright (c) 2019 Sciarra, Ciccotti, Aiello, Minosi, Munzi, Buccolieri, Peluso, Palmery and Lista. This is an open-access article distributed under the terms of the Creative Commons Attribution License (CC BY). The use, distribution or reproduction in other forums is permitted, provided the original author(s) and the copyright owner(s) are credited and that the original publication in this journal is cited, in accordance with accepted academic practice. No use, distribution or reproduction is permitted which does not comply with these terms. 